\title{
A PREDICTION MODEL FOR AROMA QUALITY OF VIETNAMESE ORTHODOX BLACK TEAS BY COMBINED MULTIVARIATE ANALYSIS OF GC/MS AND SENSORY EVALUATION DATA
}

\author{
Hoang Quoc Tuan*, Nguyen Duy Thinh, Nguyen Thi Minh Tu \\ Hanoi University of Science and Technology, School of Biotechnology and Food technology, \\ Department of Quality Management, No 1, Dai Co Viet, Hanoi, Vietnam \\ "Email: tuan.hoangquoc@hust.edu.vn; tuanhqibft@gmail.com
}

Received: 26 October 2015; Accepted for publication: 6 May 2016

\begin{abstract}
Relationships between sensory aroma and the volatile composition of 04 black tea grades from North Vietnam were studied. Consumer preference test was carried out with 80 consumers to evaluate the aroma quality of these samples. Aroma concentrate was prepared by Brewed Extraction Method (BEM) and analyzed using GC/MS. Partial Least Squares Regression (PLSR) was used to determine the relationship between the preference scores and peak area percentage data of 39 detected volatile compounds. Among these compounds, 20 compounds were determined to contribute significantly to the perceived aroma quality of OTD black teas. On the basis of these 20 compounds, a PLSR model was constructed to predict the aroma quality of OTD black teas. The results showed that this model is a useful reference for aroma quality prediction of OTD black tea grades.
\end{abstract}

Keywords: black tea, aroma quality, PLSR, prediction model.

\section{INTRODUCTION}

Black tea is a fermented tea that is consumed round the world. The major quality attributes of black teas are their appearance, colour, aroma, and taste. Among these characteristics, aroma is an essential criterion in the evaluation of sensory scores and the commercial description of tea [1]. In the case of Vietnam black tea, these important factors were determined and scored by multiplication with a weight number of 1.2 on a scale of $1-5$. Therefore, a tea quality grade and its market price are commonly decided by its aroma and taste. Quantification of black tea quality is a difficult task because of the presence of innumerable compounds and their diverse contribution to black tea quality. There are two types of black teas: Crush, Tear, Curl (CTC) black tea and Orthodox (OTD) black tea. In the OTD Black Tea process, sorting is the the final step for separating size of tea particles for more evenness. With regard to the sorting process, there is no standard for the particle size range of each grade. Therefore, the traditional grade 
names are no more than an indication of leaf size. OTD black tea is usually graded on one of seven scales from high-quality tea (OP - FBOP - P) to low-quality tea (P - BPS - F and/or D). [1]. In Vietnam, OTD black tea accounts for nearly $70 \%$ of black tea production. The rest is CTC product.

In tea, volatile flavour compounds (VFC) are present in very low quantities, i.e. $0.01 \%$ of the total dry weight, but they have high impact on the flavour of the products due to their low threshold value [2]. These VFCs can be divided into two groups. Group I compounds are mainly the products of lipid breakdown that impart an undesirable grassy odour. On the contrary, Group II compounds that impart a sweet flavoury aroma to black tea are mainly derived from terpenoids, carotenoids and amino acids. The flavour of OTD black tea depends on the ratio of of all VFC Group II to that of VFC Group I, and this ratio is the flavour index or volatile flavour compounds (VFC) index [3].

Sensory or instrumental methods are usually used for aroma analysis. Highly reliable and consistent sensory evaluation methods for testing have been developed which obviously identify the taster perception of aroma or/and flavour. However, sensory methods are sometimes expensive as well as time consuming when used properly, and cannot be implemented "on-line" or "in-line" for immediate feedback [4]. Instrumental methods can provide feedback about the individual volatile compounds associated with aroma. Those methods take many forms, but all are based on extraction, separation, identification, and qualification or/and quantification of volatile compounds either in headspace or in the actual product matrix. Instrumental methods can be run continually to provide immediate or near immediate information about the products in a short time and in a consistent and cost-effective manner [4 - 6]. Instruments could be used instead of taster in the following scenarios: (a) when a correlation between a sensory characteristic and an instrumental measurement has been established, (b) when there is a possibility that the sensory test is laborious and may damage the panellists' health, and (c) when the testing does not result in critical product-related decisions. The last one indicates that even if there is a proven relationship, sensory testing cannot completely be replaced by instrumental testing [4]. PLS regression aims at finding the components from independent $\mathrm{X}$-variables (volatile profiles) that are relevant to dependent Y-variables (aroma quality scores) and predicting the quality ranking from a set of volatile profile. Therefore, PLS is a suitable technique to describe the instrumental and sensory quality correlation [7 - 9].

For the case of Vietnam's black tea products, there is no report about the volatile constituents of OTD black tea grades and their correlation with aroma quality except one published by Hoang et al. [10]. In this publication, only little information is available about the correlation between the volatile profile and the quality ranking or grade of OTD black tea. This study presents our results about the aroma quality of different grades of Vietnam OTD black teas obtained by volatile profiling using gas chromatography - mass spectrometry and sensory analysis.

\section{MATERIALS AND METHODS}

\subsection{Materials}

A total of 4 different grades of OTD black tea samples (F, OP, P, BPS) were obtained from a factory in PhuTho, Vietnam. All tea samples were collected in 2014, kept in polymer bags $(200 \mathrm{~g} / \mathrm{bag})$ and stored in the dark at room temperature before analysis. 


\subsection{Volatile compounds analysis}

Brewed Extraction Method: Twenty grams of black tea sample were brewed with $140 \mathrm{ml}$ of deionized boiling water for $10 \mathrm{~min}$. After filtration, the filtrate was saturated with sodium chloride and extracted with $100 \mathrm{ml}$ of dichloromethane. The extract was dried over anhydrous sodium sulfate for $1 \mathrm{~h}$. After sodium sulfate was filtrated out, the solvent was removed carefully by using an evaporative concentrator. The extraction was carried out in duplicate for each sample [11].

GC-MS analysis: A Thermo trace GC Ultra gas chromatograph coupled with the DSQ II mass spectrometer was used to perform the aroma analysis on HP-5 capillary column $(30 \mathrm{~m} \times 0.25 \mathrm{~mm} \times 0.25 \mu \mathrm{m})$ with purified helium as the carrier gas at a constant flow rate of 1 $\mathrm{ml} \mathrm{min}{ }^{-1}$. The oven temperature was held at $50{ }^{\circ} \mathrm{C}$ for $3 \mathrm{~min}$, then, increased to $190{ }^{\circ} \mathrm{C}$ at a rate of $5{ }^{\circ} \mathrm{C} \mathrm{min}{ }^{-1}$ and held $1 \mathrm{~min}$. Then increased to $240{ }^{\circ} \mathrm{C}$ at a rate of $20{ }^{\circ} \mathrm{C} \mathrm{min}{ }^{-1}$, held at this temperature for $3 \mathrm{~min}$. Ion source temperature was at $200{ }^{\circ} \mathrm{C}$ and spectra was produced in the electron impact (EI) mode at $70 \mathrm{e} \mathrm{V}$. The mass spectrometer was operated in the full scan, and the peak area was determined by Xcalibur software (Thermo Technologies) [12]. Volatile compounds were identified by their electron impact mass spectrum and similarly match index.

\subsection{Consumer test}

Preparation of a liquor of tea for use in consumer tests:

Test portion: Weigh, with an accuracy of $\pm 2 \%$, a mass of tea corresponding to $2 \mathrm{~g}$ of tea per $100 \mathrm{ml}$ of liquor

Preparation of liquor: Fill the pot containing the tea sample with freshly prepared boiling water and put on the lid. Allow the tea to brew for $6 \mathrm{~min}$, and then hold the lid in place so that the infused leaf is held back; pour the liquid through the serrations into the bowl. Remove and invert the lid, transfer the infused leaf to it and place the inverted lid on the empty pot to allow the infused leaf to be inspected [13].

Consumer test: A consumer preference test had 80 consumers to assess the aroma quality of 04 OTD black tea grades. Vietnamese consumers of black tea, age between 18 and 45, were recruited from the Hanoi, Vietnam. Consumers indicated their degree of liking the aroma of products on the 9-point horizontal scales with "dislike extremely" on the left end and "like extremely" on the right end of line.

\subsection{Statistical analysis}

The chromatographic data were unit variance transformed before running a partial least square regression analysis (PLSR). PLS regression was performed by XLSTAT (Version 2013). Principal component analysis (PCA) was performed by SPAD 5.5 software (Programs developed by Optima Company, France).

\section{RESULTS AND DISCUSSION}

\subsection{Volatile compounds}

Unlike most other aromatic foods and crops, black teas contain only $0.01-0.02 \%$ volatile organic compounds (VOCs) [14]. In this study, brewed extraction was employed to obtain the 
volatile flavour components in order to characterize black tea grades flavour. The GC-MS profile of the extract shows the presence of a wide range of compounds, including terpenoids, alcohols, acids, aldehydes, ketones, esters, and long-chain hydrocarbons.

The GC-MS profile of VOCs, brewing by deionized water followed by extraction with dichloromethane, was dominated by ester and ketone compounds $(24.78 \%-33.11 \%)$, which comprise mainly of $\gamma$-ionol acetate $(14.95 \%-40.18 \%)$ and loliolide $(5.8 \%-28.5 \%)$. Other compounds such as coniferyl alcohol $(4.42 \%-7.37 \%)$, dihydroactinidiolide $(1.26 \%-8.83 \%)$ as well as (Z)-3-hexen-1-ol (2.72 \% - 5.03\%) were present in relatively high amounts (Table 1).

Table1. Volatile compounds detected in OTD Black teas by Brewed Extraction/GC-MS.

\begin{tabular}{|c|c|c|c|c|c|}
\hline \multirow[b]{2}{*}{ S.No } & \multirow[b]{2}{*}{ Compounds } & \multicolumn{4}{|c|}{ Peak area ratio, $\%$} \\
\hline & & $\begin{array}{c}\text { OP/ } \\
\text { grade } 1\end{array}$ & $\underset{2}{\text { P/grade }}$ & $\begin{array}{c}\text { BPS/ grade } \\
\mathbf{3}\end{array}$ & $\underset{4}{F / \text { grade }}$ \\
\hline 1 & (Z)-2-penten-1-ol & 0.63 & 0.8 & 0.98 & 0.8 \\
\hline 2 & hexanal & 0.95 & 1.22 & 1.6 & 1.92 \\
\hline 3 & (Z)-3-hexen-1-ol & 2.72 & 3.24 & 3.69 & 5.03 \\
\hline 4 & caproic acid & 4.39 & 0.71 & 2.2 & nd \\
\hline 5 & benzeneacetaldehyde & 1.02 & 1.21 & 1.29 & 1.72 \\
\hline 6 & 1-hexanol & 0.98 & 0.55 & 0.85 & 0.9 \\
\hline 7 & trans-linalool oxide & 1.63 & 1.26 & 0.71 & 0.59 \\
\hline 8 & $\beta$-linalool & 0.83 & 0.72 & 0.2 & 0.85 \\
\hline 9 & n-nonaldehyde & 0.8 & 0.85 & 1.04 & nd \\
\hline 10 & benzyl alcohol & 7.3 & 8.23 & 3.94 & nd \\
\hline 11 & N-ethyl succinimide & 2.82 & 3.15 & 2.58 & nd \\
\hline 12 & linalool oxide(pyranoid) & 0.98 & 0.88 & 0.34 & 0.47 \\
\hline 13 & safranal & 0.4 & 0.5 & nd & nd \\
\hline 14 & $\beta$-cyclocitral & 0.1 & nd & nd & nd \\
\hline 15 & cis-geraniol & 0.2 & 0.1 & 0.1 & 0.11 \\
\hline 16 & $\alpha$-ionol & 0.2 & 0.1 & nd & nd \\
\hline 17 & $\beta$-damascenone & 0.2 & 0.3 & 0.1 & 0.12 \\
\hline 18 & ethyl caprylate & 0.43 & 0.56 & 0.35 & nd \\
\hline 19 & T-neoclovene & 1.53 & 1.61 & nd & nd \\
\hline 20 & $\alpha$-ionone & 0.64 & 0.87 & 0.77 & nd \\
\hline 21 & $\beta$-ionone & 0.47 & 0.57 & 0.61 & 0.16 \\
\hline 22 & unknown & nd & nd & 0.49 & nd \\
\hline 23 & $\alpha$-farnesene & 0.1 & nd & nd & nd \\
\hline 24 & dihydroactinidiolide & 8.19 & 8.83 & 8.45 & 1.26 \\
\hline 25 & 2-Methylphenol (o-cresol) & 0.71 & 0.81 & 0.49 & nd \\
\hline 26 & nerodidol & 0.22 & 0.12 & nd & nd \\
\hline 27 & imidazole, 1-methyl-5-nitro & 2.12 & 2.46 & 2.18 & 0.67 \\
\hline
\end{tabular}




\begin{tabular}{llcccc}
28 & 3-hydroxy- $\beta$-damascone & 1.44 & 1.82 & 1.29 & 1.02 \\
29 & unknown & 0.16 & $\mathrm{nd}$ & $\mathrm{nd}$ & $\mathrm{nd}$ \\
30 & 2-undecen-4-ol & 1.32 & 1.55 & $\mathrm{nd}$ & $\mathrm{nd}$ \\
31 & 4-hydroxy- $\beta$-ionone & 1.05 & 0.99 & 4.54 & 3.43 \\
32 & $\gamma$-ionol acetate & 14.52 & 15.43 & 14.57 & 40.18 \\
$33 \quad$ unknown & 1.50 & 1.94 & 0.43 & 1.55 \\
$34 \quad$ unknown & 1.19 & 1.72 & 2.23 & 1.14 \\
35 & 7,8-dihydro-3,4 dihydro - $\alpha$-ionol & 1.93 & 2.56 & 0.7 & 4.54 \\
$36 \quad$ unknown & $\mathrm{nd}$ & $\mathrm{nd}$ & 1.49 & 0.76 \\
$37 \quad$ coniferyl alcohol & 7.37 & 4.42 & 5.75 & 6.00 \\
38 & loliolide & 22.09 & 22.12 & 28.47 & 11.98 \\
39 & Naphthalene & 1.33 & 3.28 & 3.28 & 7.57 \\
Terpenoid & $\mathbf{1 2 . 6}$ & $\mathbf{1 2 . 9}$ & $\mathbf{1 0 . 8}$ & $\mathbf{3 . 0}$ \\
Aldehydes & 3.17 & 3.78 & 3.93 & 3.64 \\
Alcohols & 20.3 & 19.1 & 15.55 & 11.5 \\
Esters & 14.95 & 15.99 & 14.92 & 40.18 \\
Ketones & 24.78 & 25.23 & 33.11 & 16.55 \\
Others & 18.5 & 18.4 & 17.4 & 17.9 \\
Total \% composition & $\mathbf{9 4 . 3 0}$ & $\mathbf{9 5 . 4 8}$ & $\mathbf{9 5 . 7 1}$ & $\mathbf{9 2 . 7 7}$ \\
\hline
\end{tabular}

nd: not detected;

A total of 39 compounds were detected in black tea samples, and 35 compounds have been identified and are listed in Table 1. Most of the compounds have previously been reported from black tea either on polar or non-polar GC columns by different extraction methods, viz., SDE (simultaneous distillation extraction) and Hydro-distillation in a Clevenger apparatus [14]. When volatile compounds were analyzed by PCA (Fig. 1), clear separation of BPS and F from other samples can be observed indicating that the GC profiles were quite different among these grades.

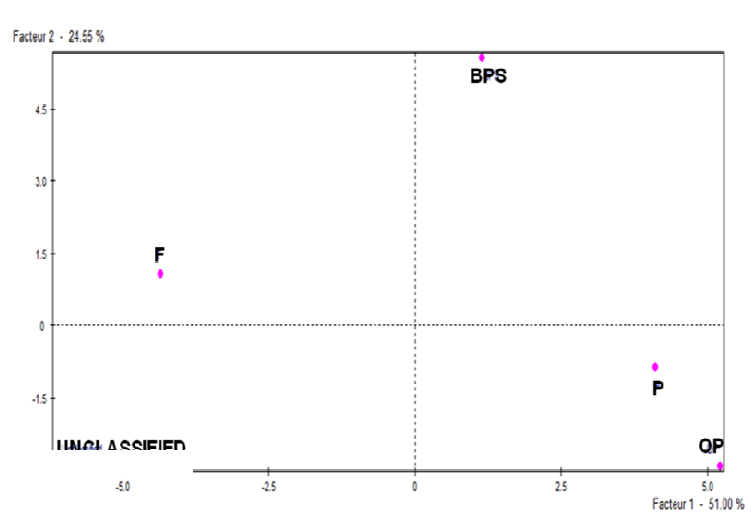

Figure 1. PCA score plots of OTD black tea samples on the two first principle components: PC1:51.00\%; PC2: $24.55 \%$.

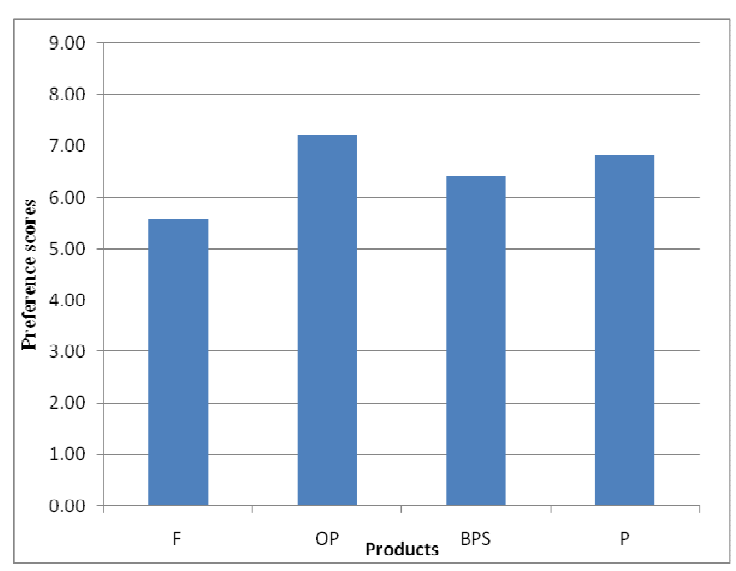

Figure 2. Preference scores of the samples. 
Separation of $\mathrm{P}$ and $\mathrm{OP}$ samples was indistinct, indicating that their aromatic profiles are much more similar in contrast to BPS and F samples. The number of detected compounds ranged from 23 in grade 4 to 37 in grade 1 . In general, high-quality teas (grades 1-2) had more volatiles than low-quality teas (grades 3-4). In other words, there was a decreasing trend in number of volatiles detected as grades went lower. The results also showed that the terpenoid and alcohols compounds in high-grade teas were higher than those of low-grade quality whereas the aldehydes compounds in high-grades were lower than those of low-grade quality.

\subsection{PLS regression}

The consumer preference test was conducted with 80 consumers to assess the aroma quality of 04 OTD black tea grades. The consumers were recruited from Hanoi- Vietnam. The results showed that OP grade was the most preferable, followed by P and BPS grades and the last is F grade $(\mathrm{p} \leq 0.05)$ (Fig. 2). As mentioned in standard for black teas, OP grades was graded as the highest quality product following by P, BPS and F.

Based on the volatiles profile which was analyzed by GC/MS and the preference scores of 04 black tea grades, further multivariate analysis i.e. Partial Least Squares Regression was applied to verify the correlation between volatile data sets and the aroma quality rankings judged from the preference sensory test. The compounds having positive or negative correlation with quality ranking could be identified from loading values of weight vectors. The validation coefficients of 39 volatile compounds obtained by the regression model are listed in Table 2.

In that, 5 compounds have both weight vectors i.e. w1 and w2 negatively correlating with sensory attributes (aroma quality), namely hexanal, (Z)-3-hexen-1-ol, benzeneacetaldehyde, 4hydroxy- $\beta$-ionone and 7,8-dihydro-3,4 dihydro - $\alpha$-ionol; while 10 compounds possessing $\mathrm{w}$ vectors positively correlating with sensory attributes, namely trans-linalool oxide, $\mathrm{n}$ nonaldehyde, N-ethyl succinimide, $\beta$-cyclocitral, cis-geraniol, $\alpha$-ionol, $\beta$-ionone, 2 methylphenol, coniferyl alcohol and loliolide. The others have negatively or positively correlating weight factors (Table 2).

Among them, (Z)-3-hexen-1-ol (-0.219), hexanal (-0.215), benzeneacetaldehyde (-0.217) and 4-hydroxy- $\beta$-ionone (-0.193) showed strong negative correlation with aroma scores (Figs. 3 and 4). $\gamma$-ionol acetate was determined to have fruit and flowers have been characterized as aroma-active compounds contributing to floral, lilac in black teas [15].

The weights $\mathrm{w}^{*}$ give information about how the variables combine to form the quantitative relation between volatile compound content (X) and sensory scores (Y). Hence, these weights are essential for understanding which $\mathrm{X}$-variables are important (numerically large $\mathrm{w}^{*}$-values).

Table 2. Correlation matrix of the variables (correlation matrix of $\mathrm{W}$ ).

\begin{tabular}{clcc}
\hline Items & Variable & $\mathrm{w}^{* 1}$ & $\mathrm{w}^{* 2}$ \\
\hline 1 & (Z)-2-penten-1-ol & -0.101 & 0.005 \\
2 & hexanal & -0.215 & -0.033 \\
3 & (Z)-3-hexen-1-ol & -0.219 & -0.073 \\
4 & caproic acid & 0.168 & 0.296 \\
5 & benzeneacetaldehyde & -0.217 & -0.102 \\
6 & 1-hexanol & -0.027 & 0.346
\end{tabular}




\begin{tabular}{|c|c|c|c|}
\hline 7 & trans-linalool oxide & 0.201 & 0.012 \\
\hline 8 & $\beta$-linalool & 0.003 & -0.155 \\
\hline 9 & n-nonaldehyde & 0.166 & 0.097 \\
\hline 10 & benzyl alcohol & 0.207 & -0.068 \\
\hline 11 & N-ethyl succinimide & 0.198 & 0.012 \\
\hline 12 & linalool oxide (pyranoid) & 0.169 & -0.101 \\
\hline 13 & safranal & 0.175 & -0.172 \\
\hline 14 & $\beta$-cyclocitral & 0.148 & 0.214 \\
\hline 15 & cis-geraniol & 0.133 & 0.213 \\
\hline 16 & $\alpha$-ionol & 0.189 & 0.040 \\
\hline 17 & $\beta$-damascenone & 0.132 & -0.277 \\
\hline 18 & ethyl caprylate & 0.195 & -0.067 \\
\hline 19 & T-neoclovene & 0.183 & -0.132 \\
\hline 20 & $\alpha$-ionone & 0.174 & -0.010 \\
\hline 21 & $\beta$-ionone & 0.156 & 0.040 \\
\hline 22 & unknown & -0.020 & 0.209 \\
\hline 23 & $\alpha$-farnesene & 0.190 & 0.045 \\
\hline 24 & dihydroactinidiolide & 0.206 & -0.043 \\
\hline 25 & 2-Methylphenol & 0.190 & 0.023 \\
\hline 26 & nerodidol & 0.187 & -0.002 \\
\hline 27 & imidazole, 1-methyl-5-nitro & 0.164 & -0.203 \\
\hline 28 & 3-hydroxy- $\beta$-damascone & 0.148 & 0.214 \\
\hline 29 & unknown & 0.178 & -0.158 \\
\hline 30 & 2-undecen-4-ol & -0.151 & 0.164 \\
\hline 31 & 4-hydroxy- $\beta$-ionone & -0.193 & -0.084 \\
\hline 32 & $\gamma$-ionol acetate & 0.032 & -0.296 \\
\hline 33 & unknown & 0.023 & 0.034 \\
\hline 34 & unknown & 0.000 & 0.000 \\
\hline 35 & 7,8-dihydro-3,4 dihydro - $\alpha$-ionol & -0.137 & -0.207 \\
\hline 36 & unknown & -0.124 & 0.180 \\
\hline 37 & coniferyl alcohol & 0.043 & 0.330 \\
\hline 38 & loliolide & 0.134 & 0.150 \\
\hline 39 & Naphthalene & -0.212 & -0.137 \\
\hline \multicolumn{4}{|c|}{ 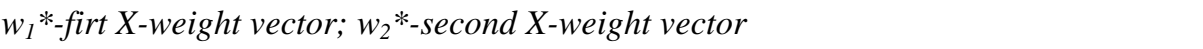 } \\
\hline
\end{tabular}

The result showed that volatile compounds disliked by consumers included hexanal, (Z)-3hexen-1-ol ; 7,8-dihydro-3,4 dihydro - $\alpha$-ionol; and benzeneacetaldehyde. 


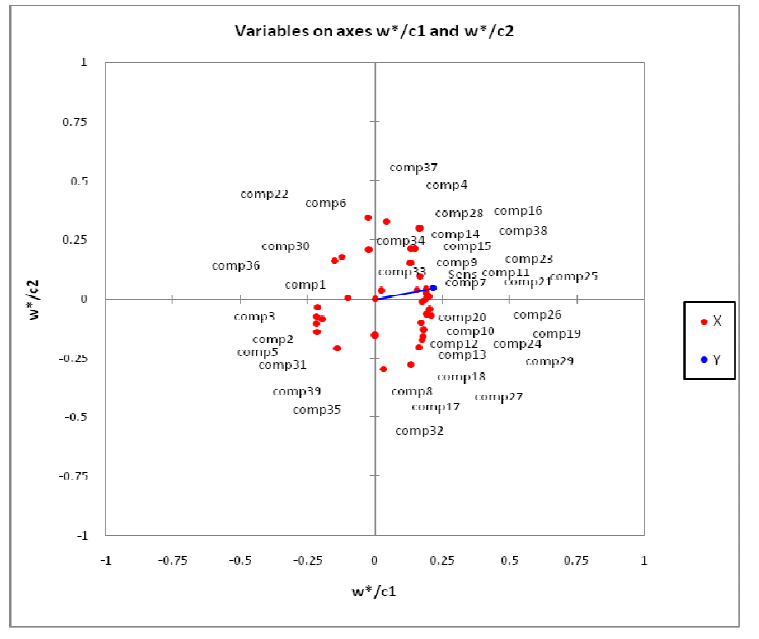

Figure 3. Variables on axes $\mathrm{w}^{*} 1 / \mathrm{c} 1$ and $\mathrm{w}^{*} 2 / \mathrm{c} 2$ with consumer preference $(\mathrm{Y})$ and volatile compounds $(\mathrm{X})$.

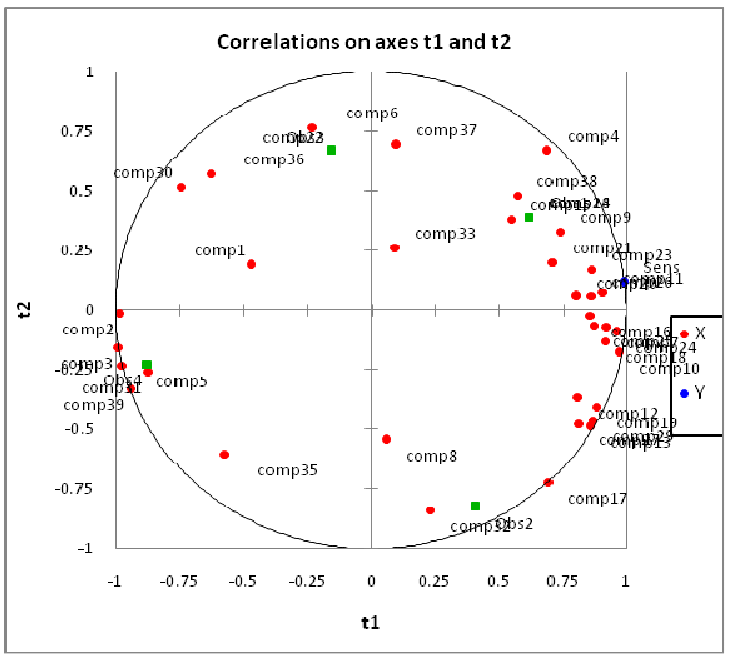

Figure 4. Correlations on axes $\mathrm{t} 1$ and $\mathrm{t} 2$ of products (obs), volatile compounds $(\mathrm{X})$ and consumer preference $(\mathrm{Y})$.

When considering the calibration sets, a good correlation between volatile profiles and sensory quality ranking could be achieved as observed from a good determination coefficient $\left(\mathrm{R}^{2}\right)$ of 0.999 . The error rate of predictability of the calibration model could be expressed from a term of root mean square error of estimation (RMSE), which was found at 0.015 . These errors counted for less than $5 \%$, indicating a reliable calibration model. The good correlation of the reliable calibration model suggested that the complexity of sensory perception could be related directly to the volatile profiles by means of multivariate analysis.

After eliminating components with VIP values $<1.0$ (Table 3), a simplified model of favourable products was obtained (1).

$$
\begin{aligned}
\mathrm{Y}= & -0.051 * \operatorname{comp} 3-0.052 * \operatorname{comp} 5-0.048 * \operatorname{comp} 2+0.041 * \operatorname{comp} 10+0.042 * \operatorname{comp} 24 \\
& +0.044 * \operatorname{comp} 7+0.041 * \operatorname{comp} 11+0.039 * \operatorname{comp} 18-0.046 * \operatorname{comp} 31+0.042 * \operatorname{comp} 25 \\
& +0.043 * \operatorname{comp} 23+0.043 * \operatorname{comp} 16+0.040 * \operatorname{comp} 26+0.033 * \operatorname{comp} 19+0.031 * \operatorname{comp} 29 \\
& +0.030 * \operatorname{comp} 13+0.037 * \operatorname{comp} 20+0.050 * \operatorname{comp} 4+0.032 * \operatorname{comp} 12+0.040 * \operatorname{comp} 9
\end{aligned}
$$

Table 3. Key compounds contributing to the construction of the predictive model.

\begin{tabular}{lllcc}
\hline No & Code & \multicolumn{1}{c}{ Compounds } & VIP & $\begin{array}{c}\text { Standardized } \\
\text { coefficients } \\
\text { Variable Sens) }\end{array}$ \\
\hline 1 & comp3 & (Z)-3-hexen-1-ol & 1.365 & -0.051 \\
2 & comp5 & benzeneacetaldehyde & 1.355 & -0.052 \\
3 & comp2 & hexanal & 1.344 & -0.048 \\
4 & comp10 & benzyl alcohol & 1.290 & 0.041 \\
5 & comp25 & 2-Methylphenol & 1.285 & 0.042 \\
6 & comp7 & trans-linalool oxide & 1.257 & 0.044 \\
7 & comp11 & succinimide, N-ethyl & 1.237 & 0.041 \\
8 & comp18 & ethyl caprylate & 1.217 & 0.039
\end{tabular}




\begin{tabular}{cllll}
9 & comp32 & $\gamma$-ionol acetate & 1.208 & -0.046 \\
10 & comp26 & nerodidol & 1.188 & 0.042 \\
11 & comp24 & dihydroactinidiolide & 1.187 & 0.043 \\
12 & comp16 & $\alpha$-ionol & 1.180 & 0.043 \\
13 & comp27 & imidazole, 1-methyl-5-nitro & 1.169 & 0.040 \\
14 & comp19 & $T$-neoclovene & 1.144 & 0.033 \\
15 & comp30 & 2-undecen-4-ol & 1.113 & 0.031 \\
16 & comp13 & safranal & 1.093 & 0.030 \\
17 & comp20 & $\alpha$-ionone & 1.087 & 0.037 \\
18 & comp4 & caproic acid & 1.050 & 0.050 \\
19 & comp12 & linalool oxide (pyranoid) & 1.057 & 0.032 \\
20 & comp9 & n-nonaldehyde & 1.040 & 0.040 \\
VIP: variable importance in the Projection & & \\
\hline
\end{tabular}

The equation of the model showed that twenty compounds significantly effect the sensory quality ranking of black teas. In that, sixteen compounds contribute to increase while four compounds contribute to decrease the aroma quality of black tea. This result could be used as a reference for developing a good aroma quality OTD black tea. This prediction model is consistent with previous studies pointing to the role of volatiles belonging to group II compounds which increase the aroma quality of black teas and vice versa for volatiles belong to group I compounds [1 - 3].

\section{CONCLUSION}

Twenty compounds were determined to contribute significantly to the perceived aroma quality of black teas, especially (Z)-3-hexen-1-ol, hexanal, benzeneacetaldehyde, benzyl alcohol, trans-linalool oxide and dihydroactinidiolide. On the basis of these 20 compounds, a model (determination coefficient of 0.999 and root mean square error of estimation of 0.015 ) was constructed to predict the aroma quality of OTD black teas. From the result obtained in this study, the volatile profiling by GC/MS in combination with sensory and PLS regression analysis could be a promising tool for aroma quality prediction of OTD black teas. To the best of our knowledge, this is the first report using GC-MS coupled with consumer liking scores in aroma quality prediction of Vietnam OTD black teas. Further investigation is needed in order to carry out study to all seven scales of quality of OTD black teas to improve the prediction model.

Acknowledgments. The authors would like to thank the Ministry of Education \& Training of Vietnam for providing financial support (Project B2015.01.110). .

\section{REFERENCES}

1. Senthil K., et al. - Chapter 4 - Black Tea: The Plants, Processing/Manufacturing and Production, in Tea in Health and Disease Prevention. Academic Press, (2013) 41-57.

2. Yang Z., Baldermann S., and Watanabe N. - Recent studies of the volatile compounds in tea, Food Research International 53(2) (2013) 585-599.

3. Ravichandran R. - Carotenoid composition, distribution and degradation to flavour volatiles during black tea manufacture and the effect of carotenoid supplementation on tea quality and aroma, Food Chemistry 78(1) (2002) 23-28. 
4. Chambers E. and Koppel K. - Associations of Volatile Compounds with Sensory Aroma and Flavor: The Complex Nature of Flavor, Molecules 18(5) (2013) 4887-4905.

5. Considine J.A. and Frankish E. - Chapter 2 - Flavors and Aromas in Foods and Beverages, in A Complete Guide to Quality in Small-Scale Wine Making, J.A. Considine and E. Frankish, Editors. Academic Press: San Diego (2014) 11-21.

6. Acampora Z., et al. - Gas chromatography-olfactometry in food flavour analysis, Journal of Chromatography A 1186(1-2) (2008) 123-143.

7. Toscas P.J., Shaw F.D., and Beilken S.L. - Partial least squares (PLS) regression for the analysis of instrument measurements and sensory meat quality data, Meat Science 52(2) (1999) 173-178.

8. Hibbert D.B. - Chemometric Analysis of Sensory Data, in Comprehensive Chemometrics, S.D. Brown, R. Tauler, and B. Walczak, Editors. Elsevier: Oxford (2009) 377-424.

9. Kirsanov D., et al. - Towards reliable estimation of an "electronic tongue" predictive ability from PLS regression models in wine analysis, Talanta 90(1) (2012) 109-116.

10. Hoang Q.T., et al. - Sensory aroma and related volatile flavor compound profiles of different black tea grades (camellia sinensis) produced in northern Vietnam. in SPISE 2014: From senses to quality-What can sensory evaluation bring to quality control. VietNam: VNU-HCM Publishing (2014).

11. Kawakami M., et al. - Aroma Composition of Oolong Tea and Black Tea by Brewed Extraction Method and Characterizing Compounds of Darjeeling Tea Aroma, Journal of Agricultural and Food Chemistry 43(1) (1995) 200-207.

12. Lin J., et al. - Discrimination of oolong tea (Camellia sinensis) varieties based on feature extraction and selection from aromatic profiles analysed by HS-SPME/GC-MS, Food Chemistry 141(1) (2013) 259-265.

13. TCVN5086-90-(ISO3103-1980), Tea-Preparation of liquor for use in sensory tests (1990).

14. Rawat R., et al. - Characterization of volatile components of Kangra orthodox black tea by gas chromatography-mass spectrometry, Food Chemistry 105(1) (2007) 229-235.

15. Pripdeevech P. and Wongpornchai S. - Chapter 26 - Odor and Flavor Volatiles of Different Types of Tea, in Tea in Health and Disease Prevention., Academic Press (2013) 307-322.

\title{
TÓM TÁT
}

\section{KÊT HỢP XỬ LÍ SỐ LIỆU ĐA CHIỀU KÊT QUẢ PHÂN TÍCH SĂC KÍ KHỐI PHỔ VÀ ĐÁNH GIÁ CẢM QUAN ĐỄ XÂY DỰNG MÔ HİNH DỬ BÁO CHẤT LƯỢNG MÙI CỦA CÁC CÂP LOẠI CHÈ ĐEN}

\author{
Hoàng Quốc Tuấn*, Nguyễn Duy Thịnh, Nguyễn Thị Minh Tú \\ Viện Công nghệ sinh học - Công nghệ thưc phẩm, Bộ môn Quản lý chất luợng, \\ Truờng Đại học Bách khoa Hà Nội, Số 1 Đại Cồ Việt, Hà Nội \\ *Email: tuanhqibft@gmail.com; tuan.hoangquoc@hust.edu.vn
}


Mối liên hệ giữa cảm quan mùi và thành phần bay hơi của 04 cấp loại chè đen sản xuất tại Việt Nam được lựa chọn để nghiên cứu. Phép thử thị hiếu người tiêu dùng trên chỉ tiêu cảm quan mùi được tiến hành trên 80 người thử. Thành phần bay hơi được thu nhận bằng phương pháp chiết nước-dung môi và phân tích bằng phương pháp sắc kí khối phổ. Phương pháp hồi quy đa biến được sử dụng để xác định mối liên hệ giữa điểm cảm quan thị hiếu và dữ liệu diện tích pick của 39 thành phần bay hơi phát hiện được. Trong số các thành phẩn bay hơi phát hiện được, có 20 chất bay hơi được xác định là có ảnh hưởng đáng kể đến cảm quan mùi của chè đen OTD. Mô hình dự báo PLSR được xây dựng để dự báo chất lượng mùi chè đen OTD. Kết quả cho thấy thành phần bay hơi thu nhận được bằng phân tích sắc kí khối phổ kết hợp với đánh giá cảm quan và xử lí số liệu đa chiều là công cụ có thể sử dụng để mô tả dự báo chất lượng mùi của chè đen ở các cấp loại khác nhau.

Tù khóa: chè đen, chất lượng mùi, PLSR, mô hình dự báo. 